\title{
SONICATION-ASSISTED PREPARATION OF CaO NANOPARTICLES FOR ANTIBACTERIAL AGENTS
}

\author{
Zhen-Xing Tang* \\ Department of Food Science, Anqing Vocational \& Technical College, 246003, Anqing, Anhui, China / Date Palm Research Center, \\ King Faisal University, P. O. Box 420, Al-hasa 31982, Saudi Arabia \\ Zhen Yu, Zhi-Liang Zhang, Xin-Yi Zhang, Qin-Qin Pan and Lu-E Shi \\ College of Life and Environmental Sciences, Hangzhou Normal University, 310016, Hangzhou, Zhejiang, China
}

Recebido em 8/7/12; aceito em 17/2/13; publicado na web em 24/5/13

\begin{abstract}
The effect of calcination conditions on the size and killing activity of $\mathrm{CaO}$ nanoparticles towards L. plantarum was studied in this paper. The results showed that $\mathrm{CaO}$ nanoparticles with a diameter of $20 \mathrm{~nm}$ could be obtained under the investigated conditions. The lethal effect of $\mathrm{CaO}$ nanoparticles after incubation of 6 or $24 \mathrm{~h}$ increased with increasing calcination time. Using CaO-SA, CaO-SB, and CaO-SC after a 24-h exposure, 2.25, 3.37, and $5.97 \log$ L. plantarum were killed, respectively, at a concentration of 100 ppm. The current results show that the use of $\mathrm{CaO}$ nanoparticles as antibacterial agents has significant potential in food-relevant industries.
\end{abstract}

Keywords: nano $\mathrm{CaO}$; preparation; antibacterial activity.

\section{INTRODUCTION}

$\mathrm{CaO}$ nanoparticles can be used as bactericides, adsorbents, and in particular as destructive adsorbents for toxic chemical agents. ${ }^{1,2}$ Few studies on the preparation of $\mathrm{CaO}$ nanoparticles have been reported. At present, methods for the preparation of $\mathrm{CaO}$ include thermal decomposition, ${ }^{3,4}$ as well as sol-gel ${ }^{5}$ and microwave processes. ${ }^{6}$ Microscale $\mathrm{CaO}$ particles can be easily obtained by decomposition of limestone (mineral $\mathrm{CaCO}_{3}$ ). Normally, $\mathrm{CaCO}_{3}$ can be decomposed at high calcination temperatures of greater than $900{ }^{\circ} \mathrm{C} .{ }^{7} \mathrm{In}$ our previous study, $\mathrm{CaO}$ nanoparticles obtained from the precursor $\mathrm{Ca}(\mathrm{OH})_{2}$ using the thermal decomposition method were reported. ${ }^{8}$ The sol-gel method is cost prohibitive on account of the high cost of the reagents and laboriousness of the process. The microwave-assisted route is another method for the synthesis of nanometal oxides, and has previously been used for preparing $\mathrm{CaO}$ nanoparticles. Roy and Bhattacharya investigated the preparation of $\mathrm{CaO}$ nanoparticles using the microwave irradiation method, with $\mathrm{Ca}\left(\mathrm{NO}_{3}\right)_{2}$ and $\mathrm{NaOH}$ as starting materials. ${ }^{6}$ Their results showed that microwave irradiation is a simple and efficient method for the production of $\mathrm{CaO}$ nanoparticles with a regular shape, small size, narrow size distribution, and high purity. Recently, sonication has been applied in the synthesis of novel nanomaterials in aqueous solutions. ${ }^{9,10}$ The chemical effect of ultrasound originates from the formation of ultrasonic cavitation, with the growth and collapse of microbubbles in the liquid phase generating very high temperatures and pressures followed by rapid cooling. These extreme conditions have been exploited for the preparation of nanoparticulate metal oxides. ${ }^{11,12}$

L. plantarum, a gram-positive bacterium, has a motionless shape and can convert lactose and other simple sugars into lactic acid. Usually, L. plantarum has complex nutritional requirements and can grow at temperatures ranging from 15 to $45^{\circ} \mathrm{C}$. Moreover, this type of bacterium is known to be very tolerant to acidity. In 1990, McDonald et al. showed that the growth of L. plantarum could be stopped when the internal $\mathrm{pH}$ reached 4.6-4.8 independently from $\mathrm{pH} 5.4-5.7$ of the culture medium. ${ }^{13}$ This feature allows $L$. plantarum to grow easily in juice drinks. ${ }^{14}$ In fact, it may metabolize citric and malic acids present in fruit juices and fruit drinks, reducing the acidity of the product.

*e-mail: tangzhenxing@126.com
In recent years, inorganic agents have been used increasingly for control of microorganisms in various applications. The key advantages of inorganic agents are improved safety and stability compared with organic antimicrobial agents. Basic metal oxides such as $\mathrm{MgO}$ and $\mathrm{ZnO}$, have been shown to exhibit antibacterial activity, where the particle size of the oxides appears to have an impact. ${ }^{15,16}$ Thus, in this work, the preparation of calcium oxide nanoparticles used as antibacterial agents by a sonication method was studied in detailed. All results obtained form the basis for further application in food-relevant fields. Until now, no relevant references on this topic have been reported.

\section{EXPERIMENTAL}

\section{Materials}

Calcium tetrahydrate $\left(\mathrm{Ca}\left(\mathrm{NO}_{3}\right)_{2} \cdot 4 \mathrm{H}_{2} \mathrm{O}\right)$ (Mallinkrodt Baker Inc, ACS), sodium hydroxide (BMD Chemicals Inc, ACS), and ethylene glycol (99\%) were purchased from BDH Inc; L. plantarum maintained in glycerol $20 \%$ solution at $-80^{\circ} \mathrm{C}$ was grown in Difco Lactobacillus media (MRS-agar and broth) at $35^{\circ} \mathrm{C}$ for $24 \mathrm{~h}$. Other reagents were obtained from local supplies.

\section{Preparation of $\mathrm{CaO}$ nanoparticles}

$\mathrm{Ca}\left(\mathrm{NO}_{3}\right)_{2} \cdot 4 \mathrm{H}_{2} \mathrm{O}(11.8 \mathrm{~g})$ was dissolved in ethylene glycol (25 $\mathrm{mL})$ and then $\mathrm{NaOH}(12.5 \mathrm{~mL} ; 2.10 \mathrm{~g})$ was added into the mixture under sonication. After $10 \mathrm{~min}$ of sonication, the solution obtained was left to stand for $5 \mathrm{~h}$. Subsequently, the precipitate was removed by filtration, washed with water, and dried at $-50{ }^{\circ} \mathrm{C}$. Finally, $\mathrm{CaO}$ nanoparticles of different sizes were obtained through calcination. The sample obtained under conditions of $530{ }^{\circ} \mathrm{C}, 5 \mathrm{~h}, 3{ }^{\circ} \mathrm{C} / \mathrm{min}$ under vacuum is denoted $\mathrm{CaO}-\mathrm{SA}$. Similarly, samples obtained under calcination conditions of $530{ }^{\circ} \mathrm{C}, 10 \mathrm{~h}, 3{ }^{\circ} \mathrm{C} / \mathrm{min}$, under vacuum, and $530{ }^{\circ} \mathrm{C}, 15 \mathrm{~h}, 3{ }^{\circ} \mathrm{C} / \mathrm{min}$, under vacuum are denoted as $\mathrm{CaO}-\mathrm{SB}$ and $\mathrm{CaO}-\mathrm{SC}$, respectively.

\section{Antibacterial effects of $\mathrm{CaO}$ nanoparticles}

Before $\mathrm{CaO}$ nanoparticles were used for antibacterial experiments, they were activated for approximately $2 \mathrm{~h}$ at $180{ }^{\circ} \mathrm{C}$. The 
activated powder samples were sterilized at $121^{\circ} \mathrm{C}$ for $15 \mathrm{~min}$, and then suspended in peptone water $(0.1 \%)$ to reach a concentration of $100 \mathrm{ppm}$.

The antibacterial effect of $\mathrm{CaO}$ nanoparticles was evaluated on $L$. plantarum. An overnight bacterial pre-culture was centrifuged, rinsed twice with sterile peptone water $(0.1 \%)$, and then re-suspended to obtain a concentration approximately $1 \times 10^{8} \mathrm{CFU} / \mathrm{mL}$. The suspension was added into 50-mL flasks containing $\mathrm{CaO}$ nanoparticles $(20$ $\mathrm{mL} ; 100 \mathrm{ppm})$. Approximately $1 \times 10^{6} \mathrm{CFU} / \mathrm{mL}$ were submitted to the stress and incubated at $24{ }^{\circ} \mathrm{C}$ with agitation $(250 \mathrm{rpm})$. Samples $(1.0 \mathrm{~mL})$ were taken at the indicated time $(6$ and $24 \mathrm{~h})$, diluted 10 -fold in distilled water, and then grown on MRS agar plate incubated at 35 ${ }^{\circ} \mathrm{C}$ for $48 \mathrm{~h}$. The enumeration was performed in $\mathrm{CFU} / \mathrm{mL}$.

\section{Characteristics analysis of $\mathrm{CaO}$ nanoparticles}

Characteristic measurements of $\mathrm{CaO}$ nanoparticles have been carried out previously by us. ${ }^{8,15-18}$ Thermal gravimetric analysis (TGA) measurements were carried out using Netzsch STA 409 Apparatus. A helium flow of $40 \mathrm{~cm}^{3} \mathrm{~min}^{-1}$ and a heating rate of $10 \mathrm{~K} \mathrm{~min}^{-1}$ were used; the size and particle size distribution was recorded in ethanol using submicron particle sizer (NICOMP 370, USA). A Rigaku Geiferflex X-ray diffractometer with Ni-filtered $\mathrm{Cu}$ Ka radiation $(40 \mathrm{kV} ; 30 \mathrm{~mA})$ was used to determine the crystallinity and phase of the samples. X-ray diffraction (XRD) patterns were recorded in the range of $20^{\circ}-70^{\circ}$ with a scan speed of $2 \%$ min. Transmission electron microscopy (TEM) photomicrographs were obtained using the Philips 201 transmission electron microscope operated at $80 \mathrm{kV}$. The deposit was scraped away from the support and then transferred to the Fromvar 1595 E (Merck) membrane-coated Cu grid (mesh 400);

\section{RESULTS AND DISCUSSION}

\section{Preparation of $\mathrm{CaO}$ nanoparticles}

\section{TGA of the intermediate}

TGA was adopted to study the decomposition characterization of the intermediates. According to TGA (Figure 1), two major weight-loss peaks were identified; 350 to $500{ }^{\circ} \mathrm{C}$ and from 500 to $700{ }^{\circ} \mathrm{C}$. The peak at $400{ }^{\circ} \mathrm{C}$ was assigned to the decomposition of $\mathrm{Ca}(\mathrm{OH})_{2}$ to $\mathrm{CaO}+\mathrm{H}_{2} \mathrm{O}$.

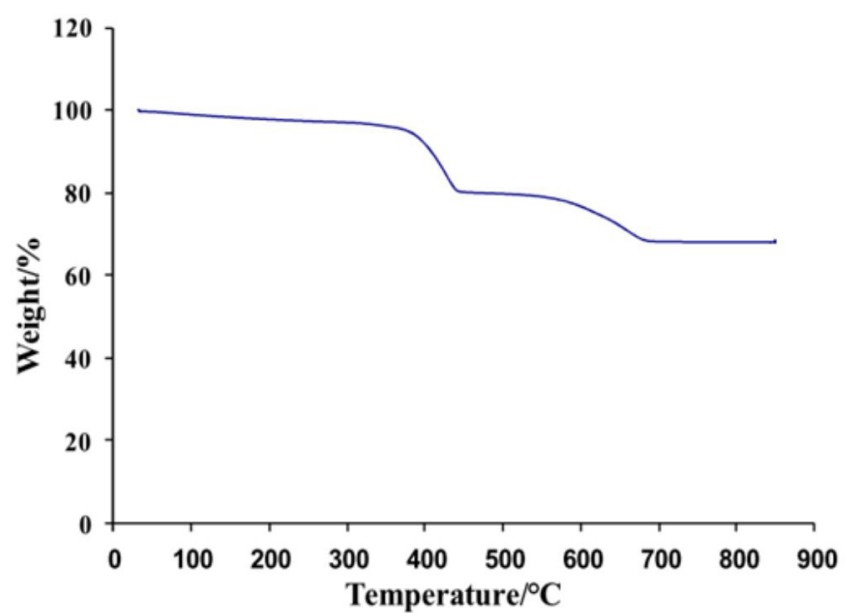

Figure 1. TGA of the intermediate. Conditions: hold for 1 min at $50{ }^{\circ} \mathrm{C}$; heat from $50^{\circ} \mathrm{C}$ to $1000{ }^{\circ} \mathrm{C}$ at a rate of $10^{\circ} \mathrm{C} / \mathrm{min}$; hold for $1 \mathrm{~h}$ at $1000^{\circ} \mathrm{C}$

This result was consistent as that previously reported by Olga et al. ${ }^{2}$ The peak from 500 to $700{ }^{\circ} \mathrm{C}$ was due to the removal of chemisorbed water. Zhu et al. (2011) reported similar findings in which the starting and completed decomposition temperatures of nano $\mathrm{CaCO}_{3}$ were 594.4 and $721.1{ }^{\circ} \mathrm{C}$, respectively. ${ }^{19} \mathrm{CaO}$ nanoparticles could be obtained through calcination at $500{ }^{\circ} \mathrm{C}$ in this study.

\section{Effect of calcination conditions on the size of $\mathrm{CaO}$ nanoparticles}

To investigate the effect of calcination temperature and calcination time on particles size, five calcination temperatures $(450,480,500$, 530 , and $\left.550{ }^{\circ} \mathrm{C}\right)$ and six calcinations times $(1,5,8,12,15$, and 20 h) were selected. The results are showed in Figures 2 and 3.

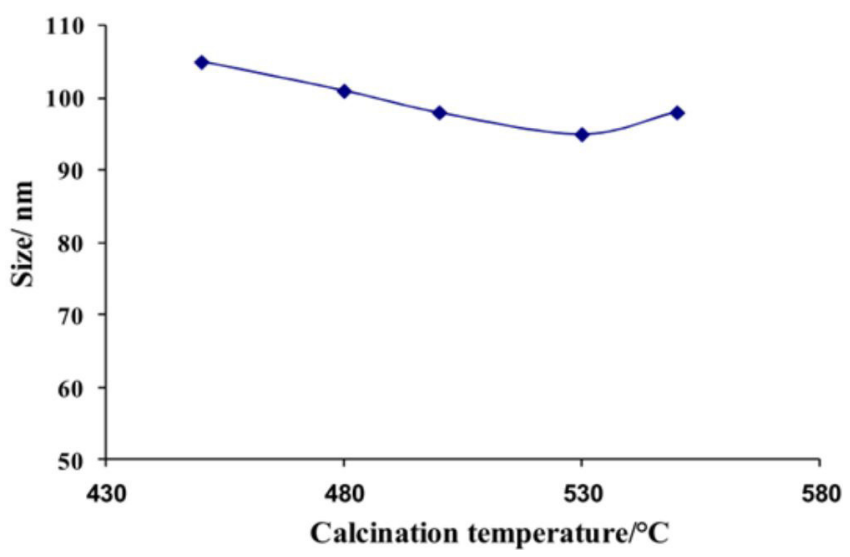

Figure 2. Effect of calcination temperature on size. Conditions: heating rate, $3{ }^{\circ} \mathrm{C} / \mathrm{min}$; calcination time, $15 \mathrm{~h}$

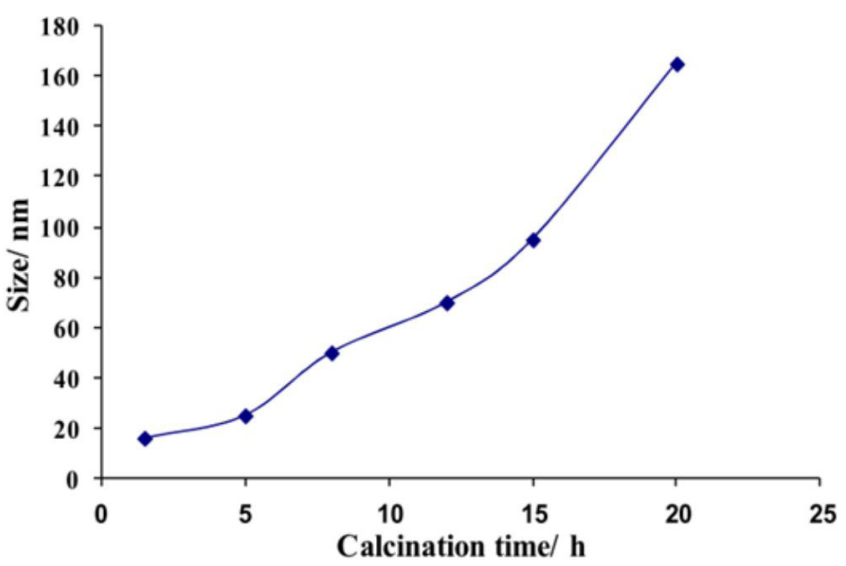

Figure 3. Effect of calcination time on size. Conditions: calcination temperature, $530{ }^{\circ} \mathrm{C}$; heating rate of calcination, $3{ }^{\circ} \mathrm{C} / \mathrm{min}$

When the calcination temperature reached above $530{ }^{\circ} \mathrm{C}$, the size of the $\mathrm{CaO}$ nanoparticles grew significantly. Below calcination temperatures of $530^{\circ} \mathrm{C}$, the decrease in $\mathrm{CaO}$ nanoparticle size with increasing calcination temperature might be explained by incomplete decomposition of the intermediates. Prolonging the calcination time at a fixed calcination temperature led to a rapid increase in nanoparticles size. Although the $\mathrm{CaO}$ nanoparticles increased as consecutive calcination time increased, the growth of these nanoparticles was not unlimited. In fact, the sintering of $\mathrm{CaO}$ is a common phenomenon that occurs simultaneously with calcination. ${ }^{15,16,18,20}$ Borgwardt (1989) studied that the sintering rate of $\mathrm{CaO}$ in an $\mathrm{N}_{2}$ atmosphere at temperatures between 700 and $1100{ }^{\circ} \mathrm{C}$ and found that the surface area and porosity of the sorbent sharply decreased as calcination temperature increased..$^{21}$ In our case, when the intermediates were decomposed at high temperatures, small $\mathrm{CaO}$ nanoparticles formed, after which the contact nanoparticles formed necks and began to grow, thus resulting 
in an increase in the average size.

The effect of the calcination heating rate on the nanoparticles was also studied. The results are presented in Figure 4.

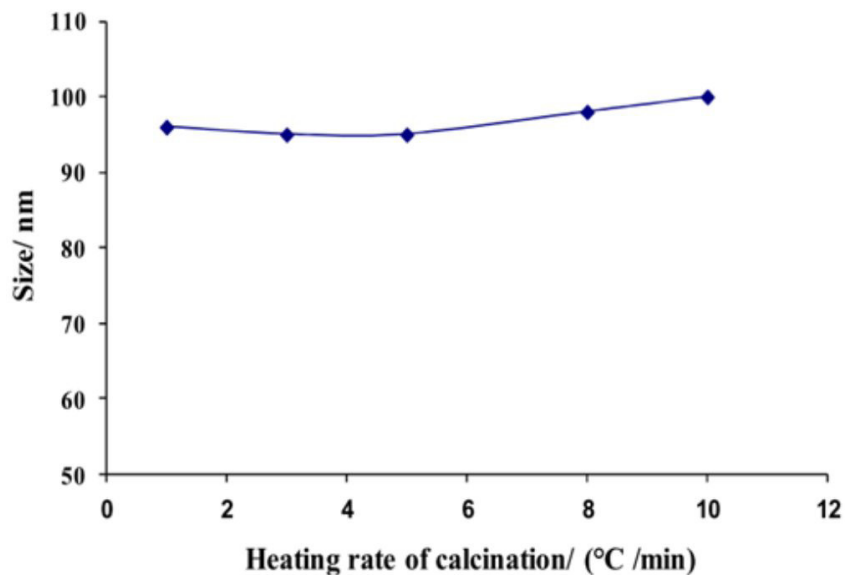

Figure 4. Effect of heating rate of calcination on size. Conditions: calcination temperature, $530{ }^{\circ} \mathrm{C}$, calcination time, $15 \mathrm{~h}$

As shown in Figure 4, the calcination heating rate had little effect on particle size. With increasing calcination heating rate, the size barely increased (i.e., from 95 to $98 \mathrm{~nm}$ ). Therefore, calcination heating rate is not a key parameter for the preparation of $\mathrm{CaO}$ nanoparticles. Usually, calcination heating rate is related to the collapse of the intermediate rate. When the heating rate of calcination is very fast, aggregation of $\mathrm{CaO}$ nanoparticles happens more easily, particularly at high calcination temperatures..$^{15,16,18}$ Therefore, a calcination heating rate of $3{ }^{\circ} \mathrm{C} / \mathrm{min}$ was selected for the preparation of $\mathrm{CaO}$ nanoparticles.

Through controlling calcination parameters, $\mathrm{CaO}$ nanoparticles with different sizes could be obtained. The size distribution of $\mathrm{CaO}$ $\mathrm{SC}$ is presented in Figure 5.

Two peaks can be observed in Figure 5. One small peak was around between $15 \mathrm{~nm}$ and $20 \mathrm{~nm}$, and another between $130 \mathrm{~nm}$ and $180 \mathrm{~nm}$. This size distribution appears closely consistent with TEM (Figure 6) and its XRD result (Figure 7). From the XRD pattern in

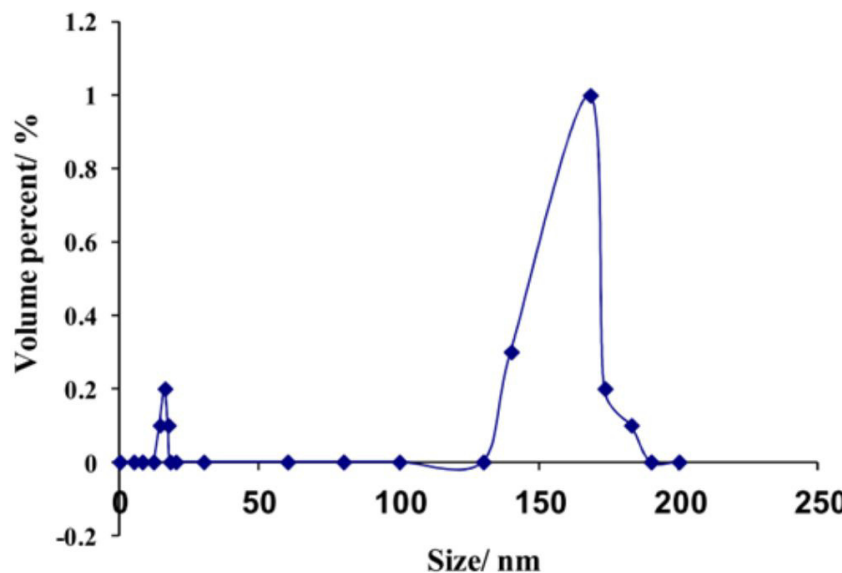

Figure 5. Size distribution of $\mathrm{CaO}$ nanoparticles. Conditions: $\mathrm{CaO}-\mathrm{SC}$

Figure 7, all peaks were consistent with the peaks of standard $\mathrm{CaO}$. XRD patterns showed broadening of the peaks, indicative of the ultra-fine nature of the crystalline material. The crystallite size calculated using Scherrer's formula was approximately $139 \mathrm{~nm}$ (Figure 7). No peaks from any other phases of $\mathrm{CaO}$ were observed.

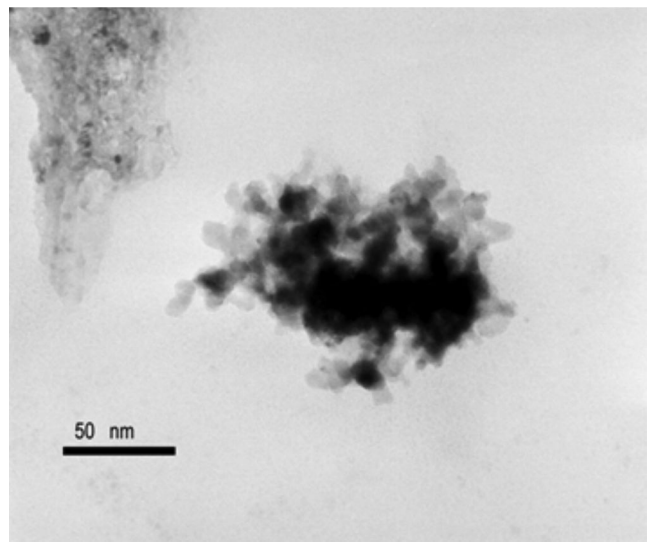

Figure 6. TEM of $\mathrm{CaO}$ nanoparticles. Conditions: $\mathrm{CaO}-\mathrm{SC}$

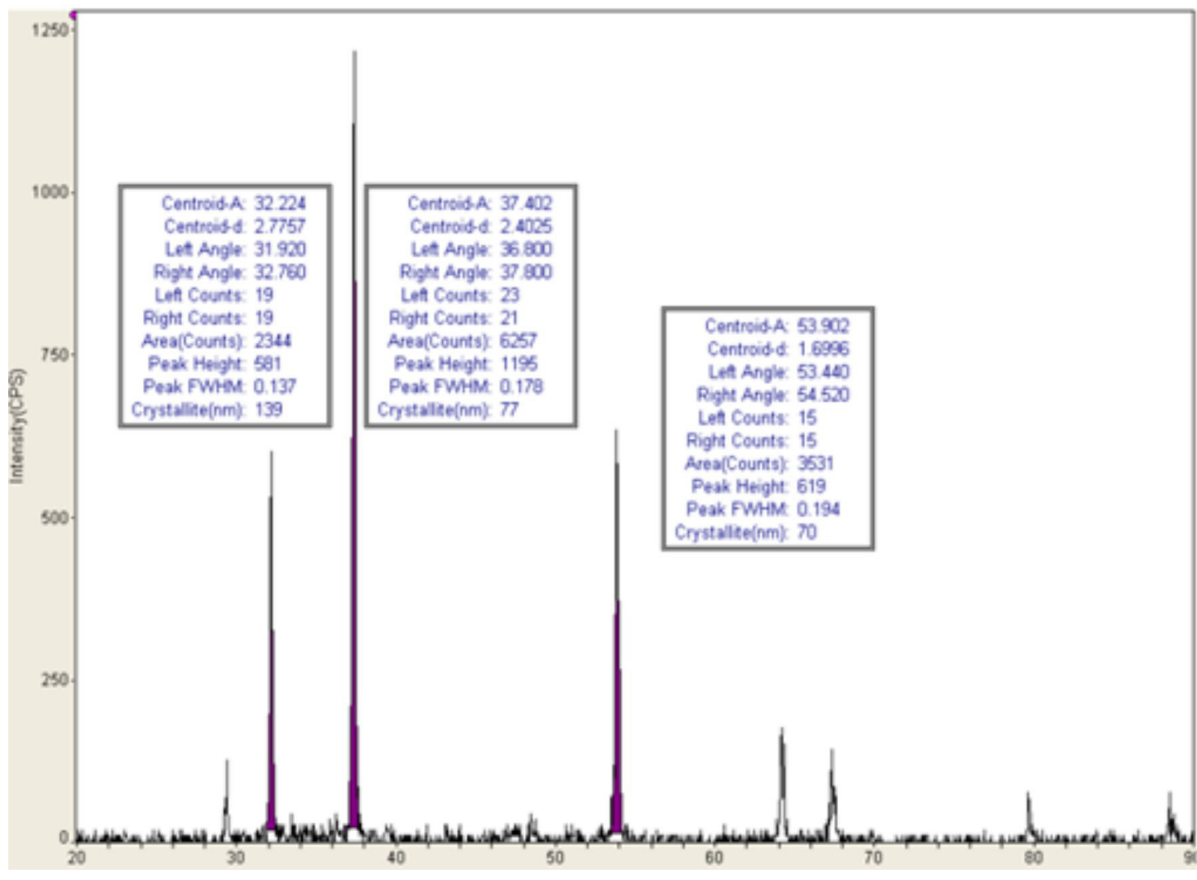

Figure 7. XRD of $\mathrm{CaO}$ nanoparticles. Conditions: $\mathrm{CaO}-\mathrm{SC}$ 


\section{Antibacterial activity of $\mathrm{CaO}$ nanoparticles}

The lethal effect of $\mathrm{CaO}$ nanoparticles is shown in Table 1. After 24-h exposure, the lethal effect of $\mathrm{CaO}$ nanoparticles increased with increasing calcination time; i.e., using $\mathrm{CaO}-\mathrm{SA}, \mathrm{CaO}-\mathrm{SB}$ and $\mathrm{CaO}-$ $\mathrm{SC}, 2.25 \log , 3.37 \mathrm{log}$ and $5.97 \mathrm{log}$ L. plantarum reductions were killed, respectively, at a concentration of $100 \mathrm{ppm}$. All CaO nanoparticles samples had little antibacterial activity after 6-h exposure. Through TGA (Figure 8), it was possible show that nanoparticles (CaO-SA) had undergone a weight loss 9\% (Figure 8-A). Impurities or chemically absorbed water could conceal active spots of nanoparticles. ${ }^{16,18}$ With increasing calcination time, antibacterial activity of $\mathrm{CaO}$ nanoparticles was also increased. When calcination time was increased to 15 and $10 \mathrm{~h}$ from TGA (Figure $8,-\mathrm{B}$, and $-\mathrm{C}$ ), $\mathrm{CaO}$ nanoparticles had a higher antibacterial activity compared with $\mathrm{CaO}-\mathrm{SA}$. For the
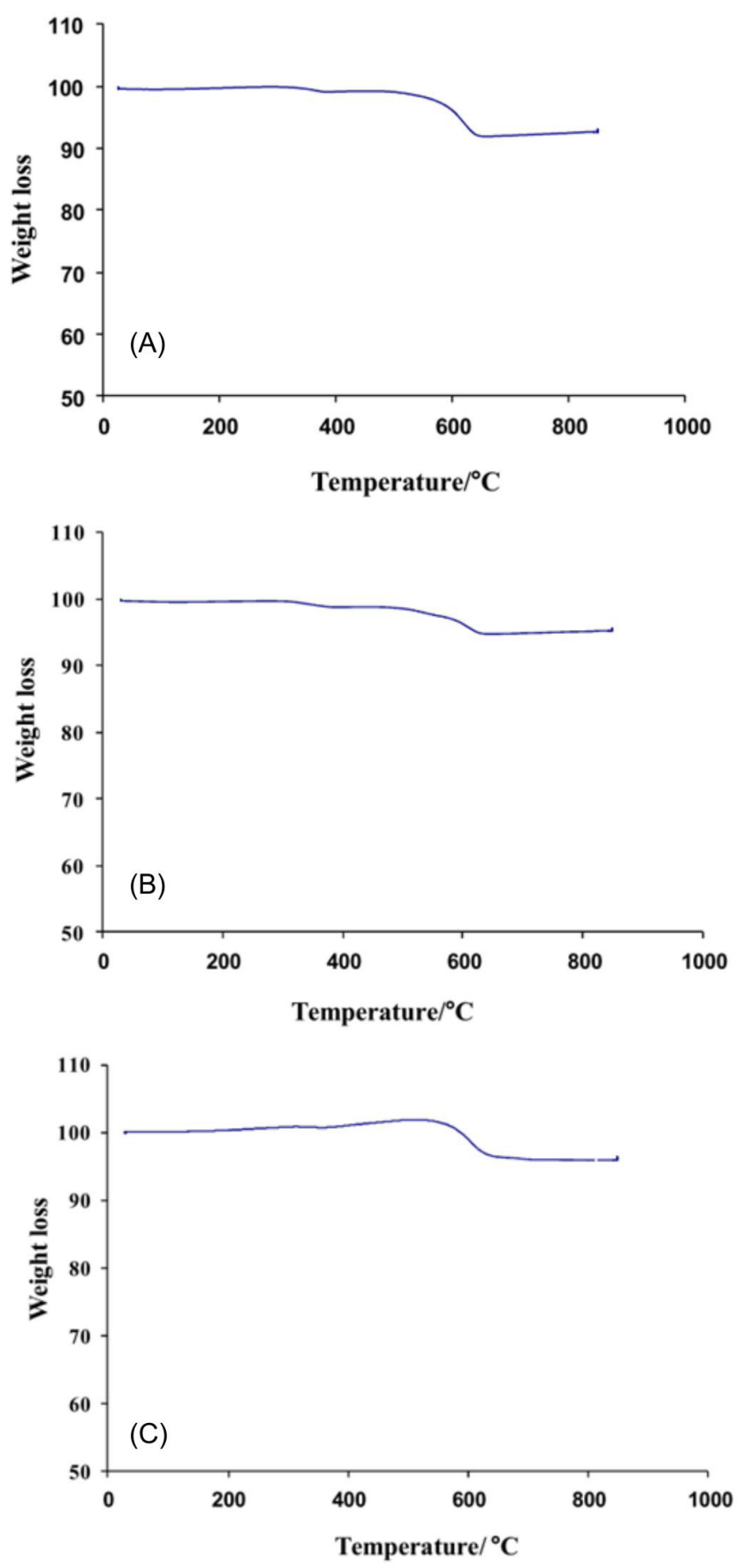

Figure 8. TGA of CaO nanoparticles. (A) CaO-SA; (B) CaO-SB; (C) CaO-SC antibacterial mechanism of $\mathrm{CaO}$ nanoparticles, it could be assumed that a concentration of $\mathrm{O}_{2}^{-}$generated from the surface increased with decreasing particle size, because the number of $\mathrm{CaO}$ powder particles per unit volume of powder slurry increased with decreasing particle size. As per the abovementioned observations, the increase in antibacterial activity was assumed to be caused by the increase in $\mathrm{O}_{2}^{-}$generated from the surface of $\mathrm{CaO}$ on reducing the sintering of the powder samples. ${ }^{2,16,18}$

Table 1. Effect of $\mathrm{CaO}$ nanoparticles on L. Plantarum viability

\begin{tabular}{llc}
\hline \multirow{2}{*}{ Samples } & \multicolumn{2}{c}{ Log Reduction } \\
\cline { 2 - 3 } & $\mathbf{6 ~ h}$ & $\mathbf{2 4} \mathbf{~ h}$ \\
\hline $\mathrm{CaO}-\mathrm{SA}, 100 \mathrm{ppm}$ & 0.08 & 2.25 \\
$\mathrm{CaO}-\mathrm{SB}, 100 \mathrm{ppm}$ & 0.12 & 3.37 \\
$\mathrm{CaO}-\mathrm{SC}, 100 \mathrm{ppm}$ & 0.18 & 5.97 \\
\hline
\end{tabular}

\section{CONCLUSIONS}

$\mathrm{CaO}$ nanoparticles as antibacterial agents were prepared by a sonication method. Nanoparticles with the smallest size of $20 \mathrm{~nm}$ could be obtained, which showed good antibacterial activity. At a concentration of $100 \mathrm{ppm}, \mathrm{CaO}-\mathrm{SC}$ could kill the quantity equivalent to L. plantarum $5.97 \log$ reductions. These results suggest that $\mathrm{CaO}$ nanoparticles from the sonication method have a potential application in food-relevant fields.

\section{REFERENCES}

1. Olga, B. K.; Isabelle, L.; Alexander, V.; Kenneth, J. K.; Chem. Mater. 1997, 9, 2468.

2. Olga, B.K.; Yong, X. L.; Kenneth J. K.; Chem. Mater. 1993, 5, 500.

3. Bellobono, I. R.; Selli, E.; Righetto, L.; Mater. Chem. Phys. 1988, 19, 13.

4. Bellobono, I. R.; Castellano, L.; Tozzi, A.; Mater. Chem. Phys.1991, 28 , 69.

5. Ghiasi, M.; Malekzadeh, A.; Cryst. Res. Technol. 2012, 47, 471.

6. Roy, A.; Bhattacharya, J.; Int. J. Nanoscience 2011, 10, 413.

7. Kasselouri, V.; Dimopoulos, G.; Parissakis, G.; Cement Concrete Res. 1995, 25, 955.

8. Tang, Z. X.; David, C.; Corcuff, R.; Belkacemi, K.; Arul, J.; Mater. Lett. 2008, 62, 2096

9. Suslick, K. S.; Hyeon, T.; Fang, M.; Chem. Mater. 1996, 8, 2172.

10. Suslick, K. S.; Price, G. J.; Annu. Rev. Mater. Sci. 1999, 29, 295.

11. Huang, W.; Tang, X.; Wang, Y.; Koltypin, Y.; Gedanken, A.; Chem. Comm. 2000, 15, 1415.

12. Wang, Y. Q.; Yin, L. X.; Palchik, O.; Hacohen, Y. R.; Koltypin, Y.; Gedanken, A.; Langmuir 2001, 17, 4131.

13. MacDonald, L. C.; Fleming, H. P.; etHassan, H. M.; Appl. Environ. Microbiol. 1990, 56, 2120.

14. Shearer, A. E. H.; Mazzotta, A. S.; Chuyate, R.; et Gombas, D. E.; J. Food Prot. 2002, 65, 1271.

15. Tang, Z. X.; Shi, L. E.; Ecl. Quím. 2008, 33, 15.

16. Shi, L. E.; Fang, X. J.; Zhang, Z. L.; Zhou, T.; Jiang, D.; Wu, H. H.; Tang, Z. X.; Int. J. Food Sci. Tech. 2012, 47, 1866.

17. Tang, Z. X.; Fang, X. J.; Zhang, Z. L.; Pan, L. X.; Zhang, X. Y.; Pan, Q. Q.; Shi, L. E.; J. Chem. Soc. Pakistan. 2012, 34, 1423.

18. Tang, Z. X.; Fang, X. J.; Zhang, Z. L.; Zhou, T.; Zhang, X. Y.; Shi, L. E.; Braz. J. Chem. Eng. 2012, 29, 775.

19. Zhu, Y. Q.; Wu, S. F.; Wang, X. Q.; Chem. Eng. J. 2011, 175, 512.

20. Liu, W. Q.; Low, N. W.; Feng, B.; Wang, G. X.; de Costa, J. C. D.; Environ. Sci. Tech. 2010, 44, 841.

21. Borgwardt, R. H.; Chem. Eng. J. 1989, 44, 53. 